Sharif University of Technology
Scientia Iranica
SCIENTIA
IRAN I CA

\title{
Numerical study of conjugate heat transfer in laminar and turbulent nanofluid flow in double pipe heat exchangers
}

\author{
H. Safikhani*, M. Ahmari and E. Azadehfar \\ Department of Mechanical Engineering, Faculty of Engineering, Arak University, Arak, P.O. Box 38156-88349, Iran.
}

Received 30 June 2015; received in revised form 2 September 2015; accepted 19 October 2015

\author{
KEYWORDS \\ Nanofluid; \\ Double pipe heat \\ exchanger; \\ Turbulent flow; \\ Heat transfer \\ enhancement; \\ Mixture model.
}

\begin{abstract}
In this paper, the conjugate heat transfer for water- $\mathrm{Al}_{2} \mathrm{O}_{3}$ nanofluid flow in double pipe heat exchangers was numerically modeled. The important parameters such as temperature distribution, local heat transfer coefficient, pressure drop, and the heat transfer rate in inner and outer fluids were evaluated and compared. All the obtained results were simultaneously analyzed for parallel and counter flows, laminar and turbulent flows, and the presence or absence of nanofluid. The nanofluid flow was modeled by employing a twophase mixture method. The findings indicate that parallel or counter flows have a more significant effect on the heat transfer performance in the laminar flow than the turbulent one. The results also show that for warming a cold fluid, the most effective mechanism is to use nanofluids in the tube containing the warm fluid. Similarly, for cooling a warm fluid, the most efficient method is to use nanofluids in the tube containing the cold fluid (using the nanofluid in the other tube).
\end{abstract}

(C) 2016 Sharif University of Technology. All rights reserved.

\section{Introduction}

The cooling and warming of fluids have important and wide-ranging applications in industrial processes such as air conditioning, refrigerating, cooling of electronic components, etc. Enhancing the heat transfer in the cooling and warming of fluids has long attracted the attention of researchers and industrialists. An important and useful way to enhance the heat transfer in tubes is the use of a nanofluid instead of a base fluid. A nanofluid refers to a compound in which solid, and mostly metallic, particles at nano sizes (usually less than $100 \mathrm{~nm}$ ) are added to an ordinary fluid, and it helps increase the value of the conductivity of mixture; thus, the nanofluid improves the amount of heat transfer in that fluid. Numerous experimental, nu-

\footnotetext{
*. Corresponding author. Tel.: +98 863664758;

Fax: +98863664758

E-mail address: h-safikhani@araku.ac.ir (H. Safikhani)
}

merical, and analytical researches have been conducted in recent years on various aspects of nanofluids [14]. A substantial increase in heat transfer along with a slight pressure drop, which is exhibited by nanofluids, compared to base fluids, has led to an extensive use of nanofluids in different types of heat exchangers including the double-pipe heat exchangers [5-9]. Akhtari et al. [6] investigated the flow of water- $\mathrm{Al}_{2} \mathrm{O}_{3}$ nanofluid in shell tube, and double-pipe heat exchangers in the laminar flow. They investigated the effects of different parameters on the behavior of nanofluid flow and observed that by using the mentioned nanofluid at $0.5 \%$ vol., the heat transfer coefficient in the double-pipe and shell tube heat exchangers increases by $13 \%$ and $26 \%$, respectively. Mohammad et al. [7], numerically, modeled the flow of different nanofluids in the double-pipe heat exchangers containing louvered strip inserts. They finally concluded that by using nanofluids and louvered strips in the flow, the amount of heat transfer increases, 
but the pressure drop goes up as well. A similar research has been previously conducted by Eiamsaard et al. [10] using a base fluid. Chavda et al. [8] experimentally evaluated the parallel/counter flows of a nanofluid in a double-pipe heat exchanger. Aghayari et al. [9] experimentally investigated the turbulent flow of a nanofluid in the double-pipe heat exchanger and realized that the use of nanofluids in this type of heat exchanger can significantly increase the heat transfer.

Based on our information, no numerical study has been carried out yet on the conjugate heat transfer of the nanofluid flow in double-pipe heat exchangers that considers the mutual effects of parallel and counter flows, laminar and turbulent flows, and the presence or absence of nanofluid on the important flow parameters such as temperature distribution, Nusselt number, heat transfer, and pressure drop values. In this paper, the water- $\mathrm{Al}_{2} \mathrm{O}_{3}$ nanofluid flow in double pipe heat exchangers has been numerically modeled. All the obtained results have been simultaneously analyzed for parallel and counter flows, laminar and turbulent flows, and the presence or absence of a nanofluid.

\section{Mathematical modeling}

\subsection{Mixture model}

In this article, numerical simulation of a nanofluid flow in the double pipe heat exchanger is performed using mixture model, which is a single-fluid two-phase method. This approach investigates equilibrium over spatial length scales. In this method, each phase has its own velocity field, and in a given control volume, there is a certain fraction of base fluid and nanoparticles. Instead of utilizing the governing equations of each phase separately, it solves the continuity, momentum, and energy equations for the mixture of phases, and the volume fraction equation for nanoparticles. The equations for the steady-state conditions are as follows:

- Continuity:

$$
\nabla \cdot\left(\rho_{m} V_{m}\right)=0 .
$$

- Momentum:

$$
\begin{aligned}
& \nabla \cdot\left(\rho_{m} V_{m} V_{m}\right)=-\nabla P+\nabla \cdot\left(\mu_{m} \nabla V_{m}\right) \\
& \quad+\nabla \cdot\left(\sum_{k=1}^{n} \varphi_{k} \rho_{k} V_{d r, k} V_{d r, k}\right)-\rho_{m, i} \beta_{m} g\left(T-T_{i}\right) .
\end{aligned}
$$

- Energy:

$$
\nabla \cdot\left(\sum_{k=1}^{n} \varphi_{k} V_{k}\left(\rho_{k} H_{k}+P\right)\right)=\nabla \cdot\left(k_{m} \nabla T\right) .
$$

- Volume fraction:

$$
\nabla \cdot\left(\varphi_{P} \rho_{P} V_{m}\right)=-\nabla \cdot\left(\varphi_{P} \rho_{P} V_{d r, P}\right),
$$

where $V_{m}$ is the mass average velocity:

$$
V_{m}=\frac{\sum_{k=1}^{n} \varphi_{k} \rho_{k} V_{k}}{\rho_{m}} .
$$

In Eq. (2), $V_{d r, k}$ is the drift velocity for nanoparticles:

$$
V_{d r, k}=V_{k}-V_{m} \text {. }
$$

The slip velocity is calculated as the velocity of nanoparticles relative to the velocity of the base fluid:

$$
V_{p f}=V_{p}-V_{f} \text {. }
$$

The relation between drift velocity and relative velocity is as follows:

$$
V_{d r, p}=V_{p f}-\sum_{k=1}^{n} \frac{\varphi_{k} \rho_{k}}{\rho_{m}} V_{f k} .
$$

The relative velocity and drag function are calculated using Manninen et al. [11] and Schiller and Naumann [12] relations, respectively, as follows:

$$
\begin{aligned}
V_{p f} & =\frac{\rho_{P} d_{P}^{2}}{18 \mu_{f} f_{\text {drag }}} \frac{\left(\rho_{P}-\rho_{m}\right)}{\rho_{P}} a, \\
f_{\text {drag }} & =\left\{\begin{array}{lll}
1+0.15 \operatorname{Re}_{P}^{0.687} & \text { for } & \operatorname{Re}_{P} \leq 1000 \\
0.0183 \operatorname{Re}_{P} & \text { for } & \operatorname{Re}_{P}>1000
\end{array}\right.
\end{aligned}
$$

The acceleration $(a)$ in Eq. (9) is:

$$
a=g-\left(V_{m} \cdot \nabla\right) V_{m} .
$$

\subsection{Turbulence modeling}

In this paper, as suggested by Namburu et al. [13], the $k-\varepsilon$ model, proposed by Launder and Spalding [14], is investigated. This model introduces two new equations: one for the turbulent kinetic energy $(k)$ and the other for turbulent dissipation rate $(\varepsilon)$. The two equations are given by:

$$
\begin{aligned}
\nabla \cdot\left(\rho_{m} V_{m} k\right)= & \nabla \cdot\left[\left(\mu_{m}+\frac{\mu_{t m}}{\sigma_{k}}\right) \nabla k\right]+G_{m}-\rho_{m} \varepsilon, \\
\nabla \cdot\left(\rho_{m} V_{m} \varepsilon\right)= & \nabla \cdot\left[\left(\mu_{m}+\frac{\mu_{t m}}{\sigma_{\varepsilon}}\right) \nabla \varepsilon\right] \\
& +\frac{\varepsilon}{k}\left(C_{1} G_{m}-C_{2} \rho_{m} \varepsilon\right),
\end{aligned}
$$

where:

$$
\begin{aligned}
& \mu_{t m}=\rho_{m} C_{\mu} \frac{k^{2}}{\varepsilon}, \\
& G_{m}=\mu_{t m}\left(\nabla V_{m}+\left(\nabla V_{m}\right)^{T}\right),
\end{aligned}
$$

with $C_{1}=1.44, C_{2}=1.92, C_{\mu}=0.09, \sigma_{k}=1$, and $\sigma_{\varepsilon}=1$. 


\subsection{Nanofluid mixture properties}

The mixture properties of $\mathrm{Al}_{2} \mathrm{O}_{3}$-water nanofluids are calculated based on the following expressions:

- Density [15]:

$$
\rho_{m}=\varphi \rho_{p}+(1-\varphi) \rho_{f} .
$$

- Specific heat capacity [16]:

$$
\left(\rho C_{p}\right)_{m}=\varphi\left(\rho C_{p}\right)_{p}+(1-\varphi)\left(\rho C_{p}\right)_{f} .
$$

- Dynamic viscosity [17]:

$$
\mu_{m}=\mu_{f}+\frac{\rho_{p} V_{B} d_{p}^{2}}{72 C \delta}
$$

where $V_{B}$ and $\delta$ are the Brownian motion of nanoparticles, and the distance between the nanoparticles is respectively calculated from:

$$
\begin{aligned}
& V_{B}=\frac{1}{d_{p}} \sqrt{\frac{18 k_{B} T}{\pi \rho_{p} d_{p}}}, \\
& \delta=\sqrt[3]{\frac{\pi}{6 \varphi}} d_{p},
\end{aligned}
$$

$C$ in Eq. (18) is defined as:

$$
C=\frac{\left(C_{1} d_{p}+C_{2}\right) \varphi+\left(C_{3} d_{p}+C_{4}\right)}{\mu_{f}},
$$

where $C_{1}, C_{2}, C_{3}$, and $C_{4}$ are given as:

$$
\begin{aligned}
& C_{1}=-0.000001133, \quad C_{2}=-0.000002771, \\
& C_{3}=0.00000009, \quad C_{4}=-0.000000393 .
\end{aligned}
$$

- Thermal conductivity [18]:

$$
\begin{aligned}
\frac{k_{m}}{k_{f}}= & 1+64.7 \varphi^{0.7460}\left(\frac{d_{f}}{d_{p}}\right)^{0.3690}\left(\frac{k_{p}}{k_{f}}\right)^{0.7476} \\
& \operatorname{Pr}_{f}^{0.9955} \operatorname{Re}_{f}^{1.2321}
\end{aligned}
$$

where $\operatorname{Re}_{f}$ and $\operatorname{Pr}_{f}$ can be expressed as:

$$
\begin{aligned}
& \operatorname{Re}_{f}=\frac{\rho k_{B} T}{3 \pi \eta^{2} \lambda_{f}}, \\
& \operatorname{Pr}_{f}=\frac{\eta}{\rho_{f} \alpha_{f}},
\end{aligned}
$$

where $\lambda_{f}$ is the MFP (mean free path) of water molecular $\left(\lambda_{f}=0.17 \mathrm{~nm}\right), k_{B}$ is Boltzmann constant $\left(k_{B}=1.3807 \times 10^{-23} \mathrm{~J} / \mathrm{K}\right)$, and $\eta$ can be defined by the following equation:

$$
\begin{aligned}
\eta & =A .10^{\frac{B}{T-C}}, & A & =2.414 \times 10^{-5}, \\
B & =247.8, & C & =140 .
\end{aligned}
$$

- Thermal expansion coefficient [19]:

$$
\beta_{m}=\left[\frac{1}{1+\frac{(1-\varphi) \rho_{f}}{\varphi \rho_{p}}} \frac{\beta_{p}}{\beta_{f}}+\frac{1}{1+\frac{\varphi}{1-\varphi} \frac{\rho_{p}}{\rho_{f}}}\right] \beta_{f} .
$$

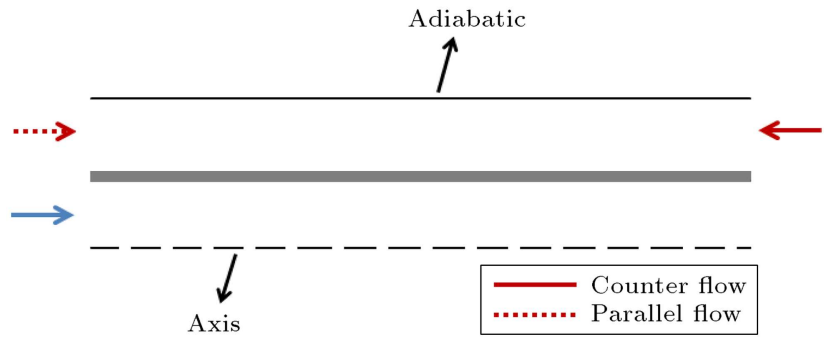

Figure 1. The schematic geometry of the double pipe heat exchanger and the related boundary conditions.

\subsection{Boundary conditions}

To numerically model the nanofluid flow in the double pipe heat exchanger, the problem is solved as an axisymmetric problem. The inner tube's central line is modeled as the axis and the outer tube wall is modeled with adiabatic boundary condition. At the inlets of tubes, the input flow velocity, temperature, and the volume fraction of nanoparticles are specified; at the outlets, the constant pressure boundary condition is applied. The schematic geometry of the double pipe heat exchanger and the related boundary conditions are shown in Figure 1.

\subsection{Numerical methods}

The numerical simulation is performed using the finite volume method. A second order upwind method is used for the convective and diffusive terms, and the SIMPLE algorithm is employed to solve the coupling of the velocity and pressure fields.

To make sure that the obtained results are independent of the size and the number of generated grids, several grids with different sizes along the axial and radial directions have been tested for each tube; and it has been attempted to consider for each tube the best grid with the highest accuracy and the lowest computation cost. Figure 2 shows a sample of grid generation for the nanofluid flow in the double pipe heat exchanger.

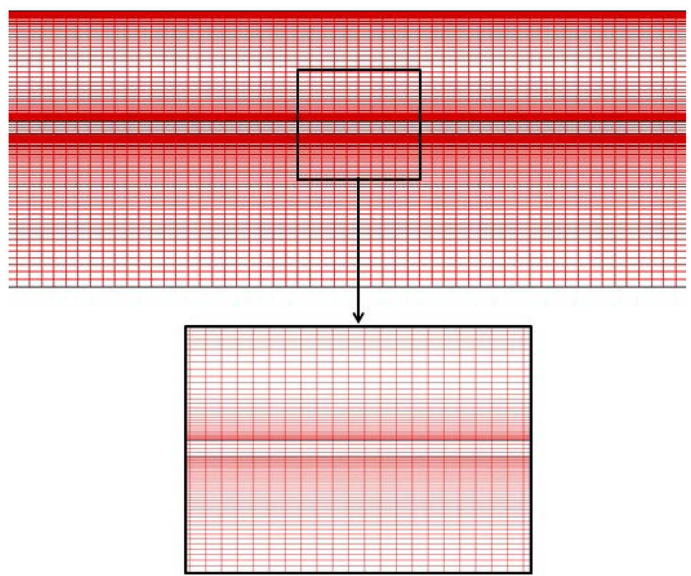

Figure 2. A sample of grid generation for the nanofluid flow in the double pipe heat exchanger. 


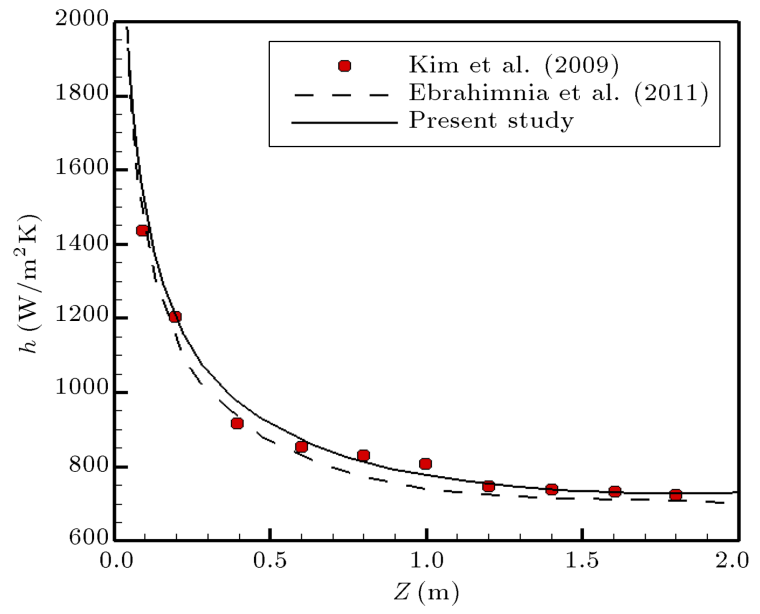

Figure 3. Comparison of local heat transfer coefficient with the available related data for the laminar flow in a circular tube; $\operatorname{Re}=1460, q^{\prime \prime}=2089 \mathrm{~W} / \mathrm{m}^{2}, d_{p}=20 \mathrm{~nm}$, and $\varphi=3 \%$.

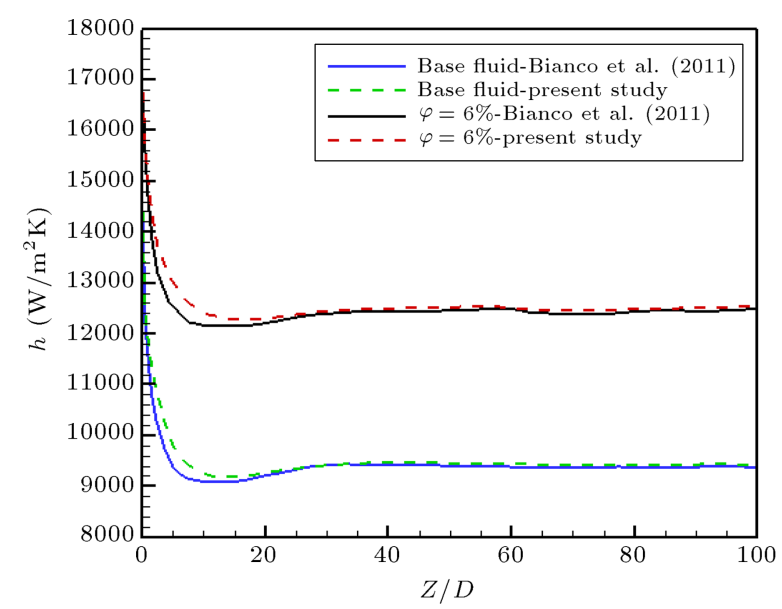

Figure 4. Comparison of local heat transfer coefficient of the present numerical simulation with the available data for the turbulent flow in the circular tube; $R e=20000$, $q^{\prime \prime}=500 \mathrm{~kW} / \mathrm{m}^{2}$, and $d_{p}=38 \mathrm{~nm}$.

\subsection{Validations}

To attain the confidence about the simulations, it is necessary to compare the results with the available related data. Figures 3 and 4 compare the local heat transfer coefficient $(h)$ in laminar and turbulent flows, respectively, in the tube of the present study with the available data of Kim et al. [20], Ebrahimnia et al. [21] (laminar flow), and Bianco et al. [22] (turbulent flow). As is evident from these figures, the present simulations agree well with the available data.

\section{Results}

In this paper, the Water- $\mathrm{Al}_{2} \mathrm{O}_{3}$ nanofluid flow in double pipe heat exchangers is numerically modeled. All the obtained results are simultaneously presented for parallel and counter flows, laminar and turbulent flows, and the presence or absence of nanofluids. In Figure 5, the axial distribution of non-dimensional temperature along with the heat exchanger for parallel and counter flows, laminar and turbulent flows, and the presence and absence of nanofluids are investigated and compared with each other. Figure 5(a) and (b) and $5(\mathrm{c})$ and $(\mathrm{d})$ indicate the distributions of temperature in the laminar and the turbulent flows, respectively. Figure 5(a) and (c) and 5(b) and (d) indicate the distributions of temperature in the parallel and the counter flows, respectively. Each of the mentioned figures illustrates four pairs of lines, with each pair indicating the mean fluid temperature in the inner and outer tubes. In the mentioned conditions in Figure 5, four different cases have been compared with each other with regard to the presence or absence of a nanofluid. In the first case, there is base fluid in both the inner and outer tubes $\left(\varphi_{i}=0, \varphi_{o}=0\right)$. In the second case, nanofluid ( $3 \%$ vol.) and base fluid exist in the inner and outer tubes, respectively $\left(\varphi_{i}=3 \%, \varphi_{o}=\right.$ $0)$. In the third case, base fluid and nanofluid (3\% vol.) exist in the inner and outer tubes, respectively. Finally, in the fourth case, both the inner and outer tubes contain nanofluids $\left(\varphi_{i}=3 \%, \varphi_{0}=3 \%\right)$. As Figure 5(a) and (c) indicate, for warming a cold fluid (inner fluid), the most effective mechanism is the use of nanofluids in the tube containing the warm fluid (outer fluid). Similarly, for cooling a warm fluid (outer fluid), the most efficient method is the use of nanofluids in the tube that contains the cold fluid (inner fluid). This means that in order to increase or reduce the temperature in each tube, it is better to use a nanofluid in the other tube.

In Figure 6, the Nusselt numbers for the inner and outer fluid flows, parallel and counter flows, laminar and turbulent flows and also for four different cases of the presence and absence of a nanofluid are analyzed and compared with each other. As is observed, in parallel flows (Figure 6(a) and (c)) at the inlets of tubes (left side of the figure), the Nusselt numbers are very large, and with the increase of the thermal boundary layer thickness along the heat exchanger, these values gradually diminish. Similarly, in counter flows (Figure 6(b) and (d)) at the inlets of tubes, from the right and left sides, the Nusselt numbers have very large values, and these values, with the increase of the thermal boundary layer thickness along the heat exchanger, gradually diminish. This figure also shows that the Nusselt number curves related to the turbulent flow (Figure 6(c) and (d)) have a flatter shape relative to the laminar flow curves (Figure 6(a) and (b)). Also, the use of nanofluid in the fluids of each inner or outer tube causes a relatively large increase in the Nusselt value of that tube.

In Figure 7, the amounts of heat transfer rate in the heat exchangers in the laminar and turbulent 


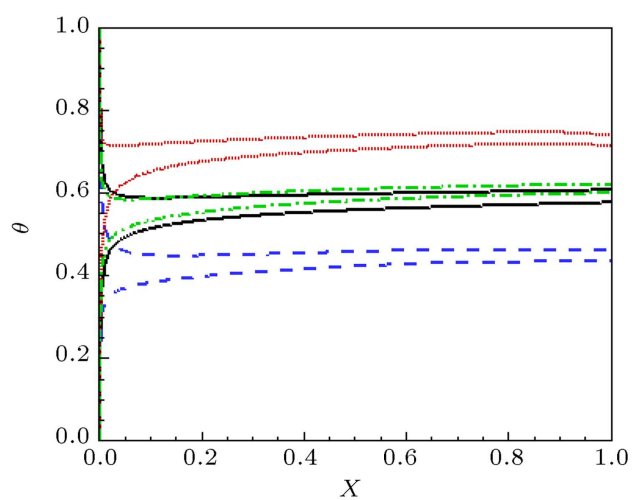

(a)

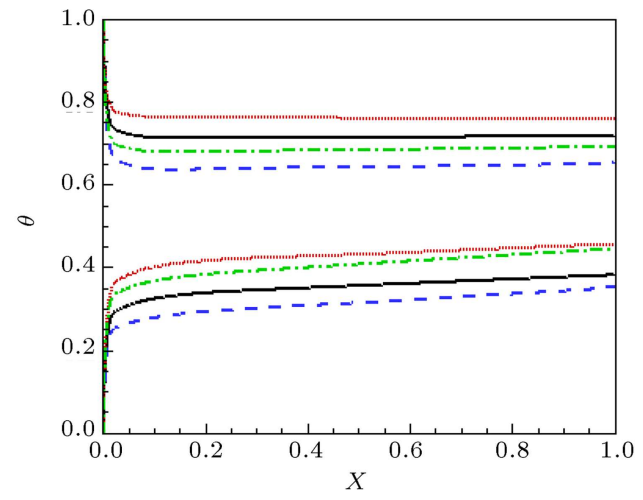

(c)

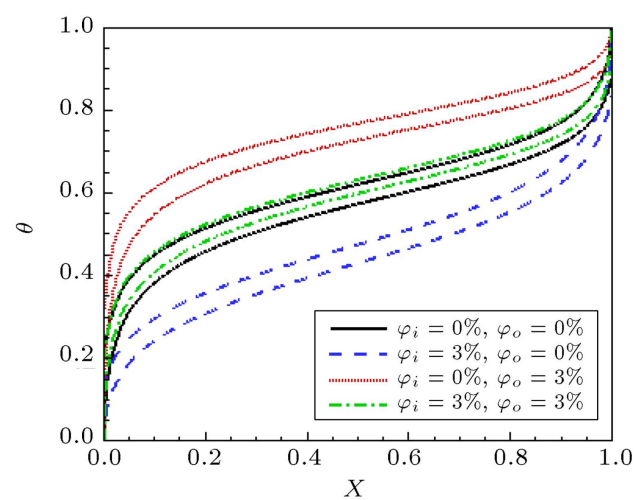

(b)

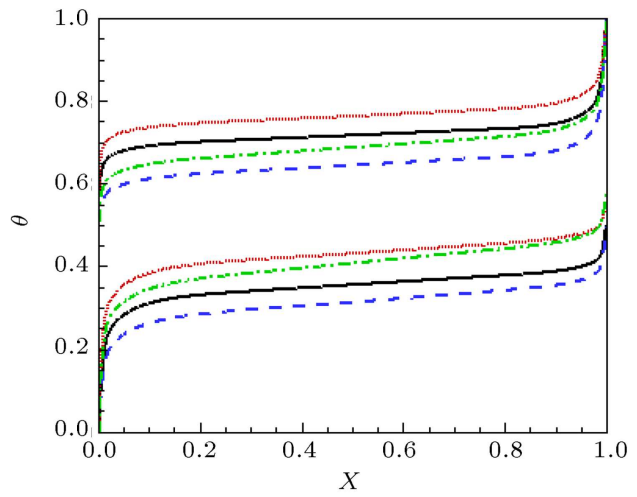

(d)

Figure 5. Dimensionless temperature distribution of the nanofluid flow in inner and outer pipes: (a) Parallel and laminar flow; (b) counter and laminar flow; (c) parallel and turbulent flow; and (d) counter and turbulent flow.

flows (Figure 7(a) and (b), respectively), parallel and counter flows (triangle and circle marks, respectively), and in the presence or absence of nanofluid (four different cases) have been compared with each other at various Reynolds numbers (Re). As is observed, in all the cases, the heat transfer increases with the increase of Re. A very important point to note in this figure is that the parallel or counter flows are very important in the laminar flow; in the turbulent flow, it is not so important. In the laminar flow, more heat is transferred in a counter flow heat arrangement than in a parallel flow heat exchanger. As is obvious, by using a nanofluid in each of the four cases, the amount of heat transfer increases. The heat exchanger with nanofluids in both of its tubes has the highest amount of heat transfer, followed by the exchanger with nanofluid in its inner tube, then the one with nanofluid in its outer tube, and finally, the exchanger that contains no nanofluid is ranked last in terms of the heat transfer rate. This figure also shows that turbulent flow (Figure $7(b)$ ) is capable of transferring more heat than laminar flow (Figure $7(\mathrm{a})$ ).

The pressure drop in the inner and outer tubes containing nanofluids under different conditions has been illustrated in Figures 8 and 9, respectively. According to these figures, in all the considered conditions, the pressure drop increases with the increase of
Re. Also, pressure drop increases slightly with the use of nanofluid. Parallel or counter flows have no effect on the amount of the pressure drop. Pressure drop is also much greater in the turbulent flow relative to laminar flow.

\section{Conclusions}

In this paper, the conjugate heat transfer of water$\mathrm{Al}_{2} \mathrm{O}_{3}$ nanofluid flow in the double pipe heat exchanger was numerically modeled. Important parameters such as temperature distribution, local heat transfer coefficient, pressure drop, and the heat transfer rate in inner and outer fluids were evaluated and compared. All the obtained results were simultaneously analyzed for the parallel and counter flows, laminar and turbulent flows, and the presence or absence of nanofluid. The nanofluid flow was modeled by employing a twophase mixture method. With regard to the presence or absence of a nanofluid, four different cases were considered: in the first case, both the inner and outer tubes lack any nanofluid; in the second case, the inner tube contains a nanofluid, while the outer tube does not; in the third case, there is no nanofluid in the inner tube, while the outer tube contains a nanofluid; and in the fourth case, both tubes contain nanofluids. In summary, the following results were obtained: 


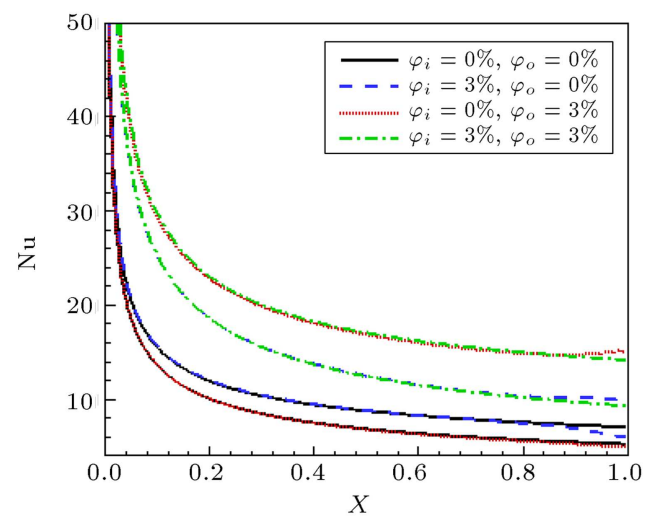

(a)

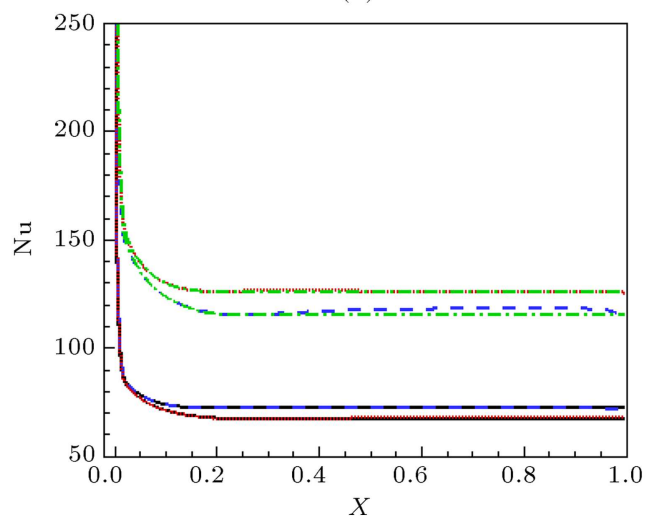

(c)

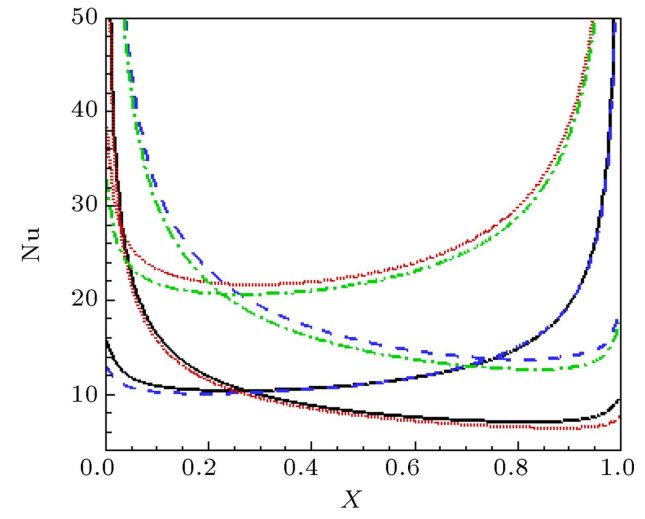

(b)

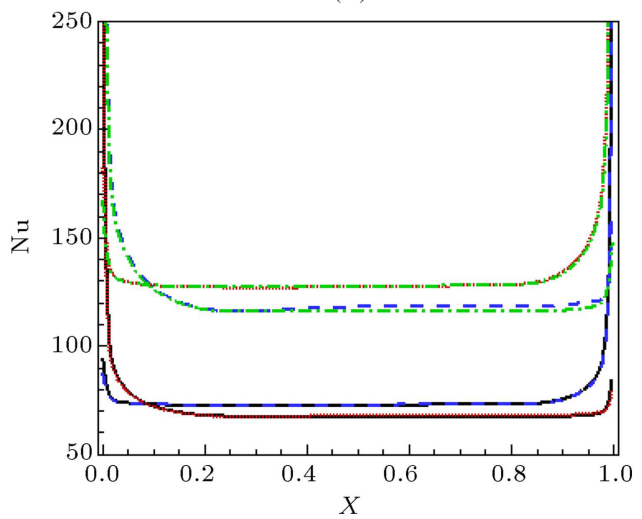

(d)

Figure 6. Local Nusselt number of nanofluid flow in inner and outer pipes: (a) Parallel and laminar flow; (b) counter and laminar flow; (c) parallel and turbulent flow; and (d) counter and turbulent flow.

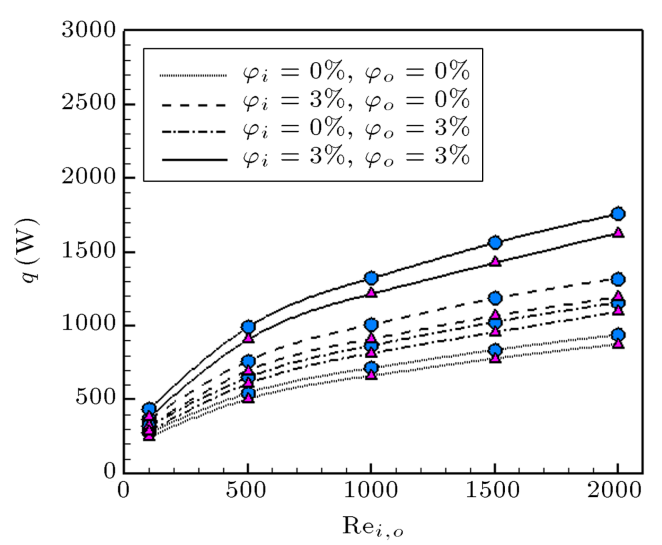

(a)

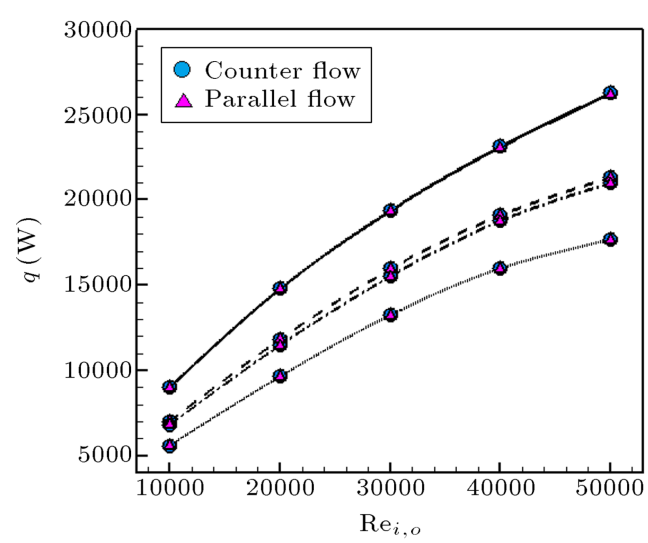

(b)

Figure 7. Variations of heat transfer rate of the double pipe heat exchanger versus Re number in (a) laminar flow, and (b) turbulent flow.

- For warming a cold fluid (inner fluid), the most effective mechanism is the use of nanofluid in the tube containing the warm fluid (outer fluid); similarly, for cooling a warm fluid (outer fluid), the most efficient method is the use of nanofluid in the tube that contains the cold fluid (inner fluid). This means that in order to increase or reduce the temperature in each tube, it is better to use a nanofluid in the other tube;
- The use of nanofluid in the fluids of each inner or outer tube causes a relatively large increase in the $\mathrm{Nu}$ of that tube;

- The heat transfer increases with the increase of Re;

- The parallel or counter flows are very important in the laminar flow; it is not so important in the turbulent flow;

- By using a nanofluid in each of the four cases, 


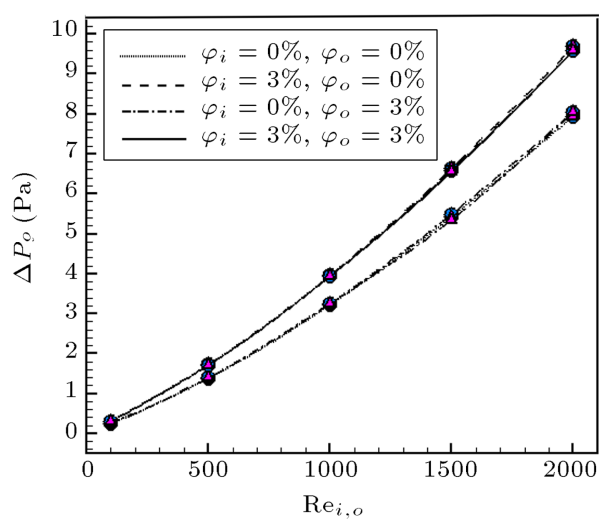

(a)

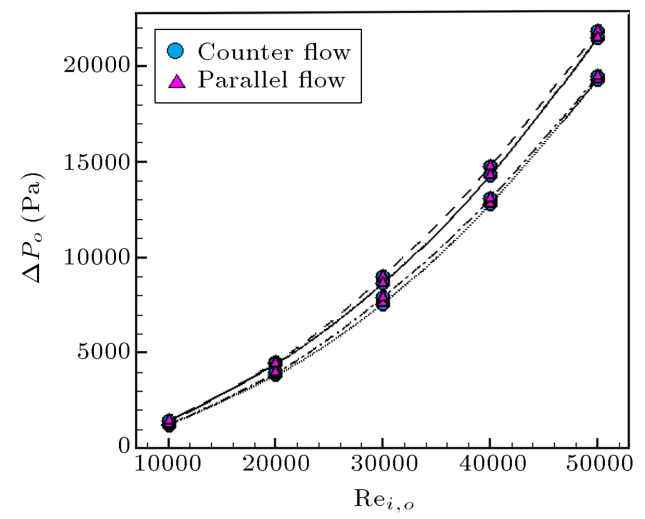

(b)

Figure 8. Variations of inner pipe pressure drop of the double pipe heat exchanger versus Re number in (a) laminar flow, and (b) turbulent flow.

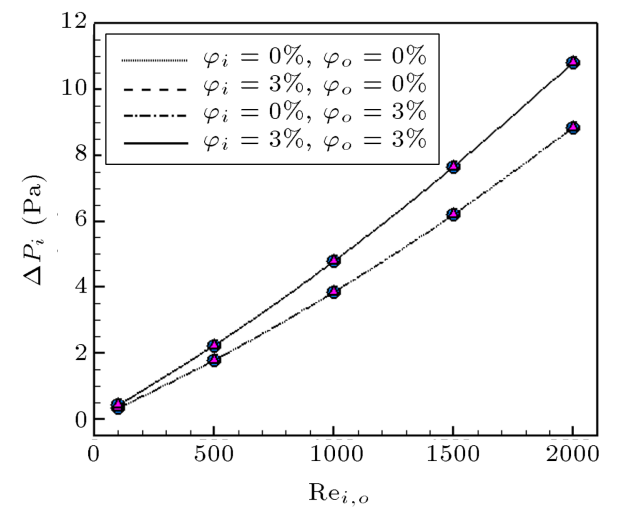

(a)

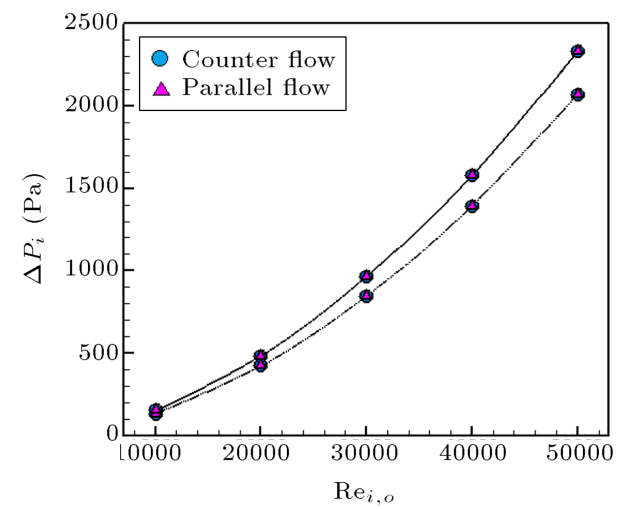

(b)

Figure 9. Variations of the outer pipe pressure drop of the double pipe heat exchanger versus Re number in (a) laminar flow, and (b) turbulent flow.

the amount of heat transfer increases. The heat exchanger with nanofluid in both of its tubes has the highest amount of heat transfer, followed by the exchanger with nanofluid in its inner tube, and then the one with nanofluid in its outer tube, and finally the exchanger that contains no nanofluid is ranked last in terms of the heat transfer rate;

- Turbulent flow is capable of transferring more heat than laminar flow;

- Pressure drop increases with the increase of Re. Also, pressure drop increases slightly with the use of nanofluid;

- Parallel or counter flows have no effect on the amount of pressure drop;

- Pressure drop is also much greater in turbulent flow relative to laminar flow.

\section{Nomenclature}

$\begin{array}{ll}a & \text { Acceleration }\left(\mathrm{m} \mathrm{s}^{-2}\right) \\ C_{p} & \text { Specific heat }\left(\mathrm{J} \mathrm{kg}^{-1} \mathrm{~K}^{-1}\right)\end{array}$

C Constant in Eq. (18)

$D_{h} \quad$ Hydraulic diameter of tubes $(\mathrm{m})$

$d_{p} \quad$ Diameter of nanoparticles $(\mathrm{m})$

$f \quad$ Skin friction coefficient

$g \quad$ Gravitational acceleration $\left(\mathrm{m} \mathrm{s}^{-2}\right)$

$h \quad$ Local heat transfer coefficient (W $\mathrm{m}^{-2} \mathrm{~K}^{-1}$ )

$k \quad$ Thermal conductivity $\left(\mathrm{W} \mathrm{m}^{-1} \mathrm{~K}^{-1}\right)$

$k_{B} \quad$ Boltzmann constant $\left(=1.3807 \times 10^{-23}\right.$ $\mathrm{J} \mathrm{K}^{-1}$ )

$L \quad$ Length of tubes $(\mathrm{m})$

$\mathrm{Nu} \quad$ Nusselt number $\left(=h D_{h} / k\right)$

$P \quad$ Pressure $(\mathrm{Pa})$

Pr Prandtl number $\left(=\alpha_{m} / \nu_{m}\right)$

$q^{\prime \prime} \quad$ Heat flux $\left(\mathrm{W} \mathrm{m}^{-2}\right)$

Re Reynolds number $\left(=V D_{h} / \nu_{m}\right)$

$T$ Temperature (K)

$V \quad$ Velocity $\left(\mathrm{m} \mathrm{s}^{-1}\right)$ 
Width of flat tube $(\mathrm{m})$

\section{Greek symbols}

$\alpha \quad$ Thermal diffusivity $\left(=k / \rho C_{p}\right)$

$\theta \quad$ Dimensionless temperature $(=$ $\frac{T-T_{c, i}}{T_{h, i}-T_{c, i}}$ )

$\phi \quad$ Nanoparticles volume fraction

$\lambda_{f} \quad$ Mean free path of water molecular $(\mathrm{m})$

$\mu \quad$ Dynamic viscosity $\left(\mathrm{N} \mathrm{s} \mathrm{m}^{-2}\right)$

$\nu \quad$ Kinematic viscosity $\left(\mathrm{m}^{2} \mathrm{~s}^{-1}\right)$

$\rho \quad$ Density $\left(\mathrm{kg} \mathrm{m}^{-3}\right)$

\section{Subscripts}

\section{BF Base Fluid}

$d r \quad$ Drift

$f \quad$ Fluid

$i \quad$ Inner

$k \quad$ Indices

$m \quad$ Mixture

o $\quad$ Outer

$p \quad$ Nanoparticle phase

$w \quad$ Wall

\section{References}

1. Das, S., Putra, N., Thiesen, P. and Roetzel, R. "Temperature dependence of thermal conductivity enhancement for nanofluids", Journal of Heat Transfer, 125, pp. 567-574 (2003).

2. Murshed, S., Leong, K. and Yang, C.A. "Combined model for the effective thermal conductivity of nanofluids", Applied Thermal Engineering, 29, pp. 2477-2483 (2009).

3. Teng, T., Hung, Y., Teng, T., Mo, H. and Hsu, H. "The effect of alumina/water nanofluid particle size on thermal conductivity", Applied Thermal Engineering, 30, pp. 2213-2218 (2010).

4. Safikhani, H. and Abbassi, A. "Effects of tube flattening on the fluid dynamic and heat transfer performance of nanofluid flow", Advanced Powder Technology, 25(3), pp. 1132-1141 (2014).

5. Huminic, G. and Huminic, A. "Application of nanofluids in heat exchangers: A review", Renewable and Sustainable Energy Reviews, 16, pp. 5625-5638 (2012).

6. Akhtari, M., Haghshenasfard, M. and Talaie, M.R. "Numerical and experimental investigation of heat transfer of $\alpha-\mathrm{Al}_{2} \mathrm{O}_{3} /$ water nanofluid in double pipe and shell and tube heat exchangers", Numerical Heat Transfer, Part A, 63, pp. 941-958 (2013).

7. Mohammed, H.A., Hasan, H.A. and Wahid, M.A. "Heat transfer enhancement of nanofluids in a double pipe heat exchanger with louvered strip inserts", Inter- national Communications in Heat and Mass Transfer, 40, pp. 36-46 (2013).

8. Chavda, N.K., Patel, J.R., Patel, H.H. and Parmar, A.P. "Effect of nanofluid on heat transfer characteristics of double pipe heat exchanger: Part-i: Effect of aluminum oxide nanofluid", International Journal of Research in Engineering and Technology, 3(12), pp. 42-52 (2014).

9. Aghayari, R., Maddah, H., Ashori, F. and Aghili, M. "The experimental study of nanoparticles effect on thermal efficiency of double pipe heat exchangers in turbulent flow", Transport Phenomena in Nano and Micro Scales, 2, pp. 140-148 (2014).

10. Eiamsa-ard, S., Pethkool, S., Thianpong, C. and Promvonge, P. "Turbulent flow heat transfer and pressure loss in a double pipe heat exchanger with louvered strip inserts", International Communications in Heat and Mass Transfer, 35, pp. 120-129 (2008).

11. Manninen, M., Taivassalo, V. and Kallio, S., On the Mixture Model for Multiphase Flow, VTT Publications (1996).

12. Schiller, L., Naumann, A.Z. Ver. "A drag coefficient correlation", Deutsch. Ing., 77, pp. 318-320 (1935).

13. Namburu, P.K., Das, D.K., Tanguturi, K.M. and Vajjha, R.S. "Numerical study of turbulent flow and heat transfer characteristics of nanofluids considering variable properties", International Journal of Thermal Sciences, 48, pp. 290-302 (2009).

14. Lauder, B.E. and Spalding, D.B., Lectures in Mathematical Models of Turbulence, Academic Press, London (1972).

15. Pak, B. and Cho, Y. "Hydrodynamic and heat transfer study of dispersed fluids with submicron metallic oxide particles", Experimental Heat Transfer, 11, pp. 151170 (1998).

16. Xuan, Y. and Roetzel, W. "Conceptions for heat transfer correlation of nanofluids", International Journal of Heat and Mass Transfer, 43, pp. 3701-3707 (2000).

17. Masoumi, N., Sohrabi, N. and Behzadmehr, A. "A new model for calculating the effective viscosity of nanofluids", Journal of Applied Physics, 42, 055501 (2009).

18. Chon, C., Kihm, K., Lee, S. and Choi, S. "Empirical correlation finding the role of temperature and particle size for nanofluid $\left(\mathrm{Al}_{2} \mathrm{O}_{3}\right)$ thermal conductivity enhancement", Journal of Applied Physics, 87(3), 153107 (2005).

19. Khanafer, K., Vafai, K. and Lightstone, M. "Buoyancy driven heat transfer enhancement in a two dimensional enclosure utilizing nanofluids", International Journal of Heat and Mass Transfer, 46, pp. 3639-3653 (2003).

20. Kim, D., Kwon, Y., Cho, Y., Li, C., Cheong, S., Hwang, Y., Lee, J., Hong, D. and Moon, S. "Convective heat transfer characteristics of nanofluids under 
laminar and turbulent flow conditions", Current Applied Physics, 9(2), pp. 119-123 (2009).

21. Ebrahimnia-Bajestan, E., Niazmand, H., Duangthongsuk, W. and Wongwises, S. "Numerical investigation of effective parameters in convective heat transfer of nanofluids flowing under a laminar flow regime", International Journal of Heat and Mass Transfer, 54, pp. 4376-4388 (2010).

22. Bianco, V., Manca, O. and Nardini, S. "Numerical investigation on nanofluids turbulent convection heat transfer inside a circular tube", International Journal of Thermal Sciences, 50, pp. 341-349 (2011).

\section{Biographies}

Hamed Safikhani is an Assistant Professor of Mechanical Engineering at the Arak University, I.R. Iran. He received his $\mathrm{PhD}$ from the Amirkabir University of Technology in 2014. He is one of the members of "The Promised SORAYYA Technologist" science-based industries in I.R. Iran. He has co-authored more than 20 journals and conference publications. His research interests include two-phase and single-phase convective heat transfers at the macro-, micro-, and nano-scales.
$\mathrm{He}$ is currently working on the augmentation of heat transfer by different passive techniques in two-phase flow and also nanofluid single-phase flow.

Miad Ahmari was born in 1992 in Arak, I.R. Iran. He passed the bachelor school in Mechanical Engineering in Arak University in 2015. His bachelor dissertation was "Numerical study of Turbulent nanofluid flow in double pipe heat exchangers" under the supervision of Dr. Hamed Safikhani. He is currently working on the augmentation of heat transfer by different passive techniques in single-phase flow systems.

Erfan Azadehfar was born in Yazd, I.R. Iran in 1992. He passed the bachelor school in Mechanical Engineering in Arak University in 2015. He was a member of Student Mechanical Engineering Forum for four semesters and was the director of the forum for a semester during his studies in Arak University. His bachelor dissertation was "Numerical study of laminar nanofluid flow in double pipe heat exchangers" under the supervision of Dr. Hamed Safikhani. He is currently working on the augmentation of heat transfer by different passive techniques in single-phase and flow systems. 